\title{
TAILORING OF SPECIFICATIONS FOR RANDOM VIBRATION TESTING OF MILITARY AIRBORNE EQUIPMENTS FROM MEASUREMENT
}

\author{
Bipin Kumar Das', Prakash Kumar ${ }^{2}$ \\ ${ }^{1}$ Research Scholar, Dept. of Production Engg., B.I.T Sindri, Jharkhand, India \\ ${ }^{2}$ Assistant Professor, Dept. of Production Engg., B.I.T Sindri, Jharkhand, India
}

\begin{abstract}
Every Military Airborne Equipment needs to be subjected to Environmental Conditions for its Qualification and Acceptance. As a guideline, the standard environmental conditions are generally taken from MIL-STD 810 which is followed as a sacrosanct document for all environmental testing followed in US Department of Defence. Random Vibration Testing is also one particular environmental testing activity and the levels are defined in MIL-STD 810. It also gives the spectrum depending on the zone where the equipment is installed, for which the equipment is to be qualified. Generally the specification is arrived based on the measurements and analysis performed and recorded over the period of years in different aircraft at different zones. The MILSTD also suggests taking the test levels as a guideline only if the measured results are not available and if plausible the measurement may be undertaken and test levels may be tailored. It was observed that generally the test levels suggested in the MIL-STD are relatively stringent resulting in over-testing and in turn over-design of the equipment. In this work, a process is arrived by which the specifications could be tailored from the measured data and ensure that the equipment is tested optimally. The process involves in-flight vibration measurement in all phase of flight (taxi, takeoff, climb, cruise, descent and landing) through the accelerometers and the data acquisition system and software. The auto-power spectral density directly obtained from the software is extracted and the maximum of all phases is considered as the measured vibration spectrum. From the measured acceleration power spectral density spectrum, the Vibration Response Spectrum is obtained for the frequency range of $20 \mathrm{~Hz}$ to $2000 \mathrm{~Hz}$. The enveloping of the vibration response spectra is carried out iteratively through trial and error with minimal break points and constant slope lines to find the input PSD spectrum what is proposed for acceptance testing. Further, the qualification testing is done by adding additional $6 \mathrm{~dB}$ margin to the proposed acceptance testing levels. As a case study, the process is applied for an LRU installed in Airborne Early Warning and Control Aircraft which is in advanced stage of development.
\end{abstract}

Keywords: Random vibration, Vibration Response Spectra, Power Spectral Density (PSD)

\section{INTRODUCTION}

Every component before installing into the aircraft must qualify the different type of testing. Random vibration testing is one of them. Random vibration closely represents the real operating environment compare to the sinusoidal vibration. For testing the any component some standards are followed. Generally $M I L-S T D 810$ are used as a guidance for vibration testing. It defines the technical description regarding type of test, duration of test and also the vibration level required for any component.

Any testing standard should have following property

* It should be at least so severe that it represents the severity of real environment.

* It should not over test the components.

Many times it Found that the test levels suggested by the $M I L-S T D$ are relatively stringent resulting in over-testing and in turn over-design of the equipment and also it consumes the useful life of component so the cost. The problem was due to non - availability of true measured vibration data through which aircraft subjected, so this problem can be reduced by measuring the real vibration data of equipments(of LRU) and then optimal test level generated by this measured data. A case study of measurement and its results Vis-a-Vis the Mil Standard $810 \mathrm{~g}$ Random Vibration qualification levels is shown. Further, the tailoring methodology from measurement to qualification adopted is also explained.

\section{REVIEW OF BACKGROUND THEORY- RANDOM VIBRATION SPECTRA (RVS), POWER SPECTRAL DENSITY (PSD) AND VIBRATION RESPONSE SPECTRA:}

\subsection{Random Vibration Spectra}

Random vibration is random in nature, past knowledge can only predict the probability of occurrence of its magnitude within a particular range, but it cannot be tell about what is its precise magnitude at any instant of time. It is unique in the sense that random vibration contains all the frequency at the same within a specified frequency range. Random vibration closely represents the real environment hence due 
to this in present day random vibration testing is done in place of sine testing.

\subsection{Power Spectral Density (PSD)}

In Frequency domain, random vibration expressed in terms of power spectral density. Power spectral density measures the distribution of magnitude of vibration energy or power with respect to its frequency. APSD means acceleration power spectral density it measures the power intensity of measured acceleration. Mathematically power spectral density is the Fourier transformation of autocorrelation function. $(\tau)$ is the autocorrelation function of any sample $f(\tau)$ then the power spectral density

$$
S_{f}(\mathrm{w})=\int_{-\infty}^{\infty} R_{f}(\tau) e^{-i w \tau} d \tau
$$

\subsection{Line Replaceable Unit (LRU)}

LRU is a piece of hardware in spacecraft, ship, or aeroplane that is designed for quick replacement. LRU is generally a sealed unit and it performs the different types of logistic and control operations. For ex: the Fire strike, the first solidstate laser (SSL) weapon, designed as a line replaceable unit (LRU) for battlefield applications.

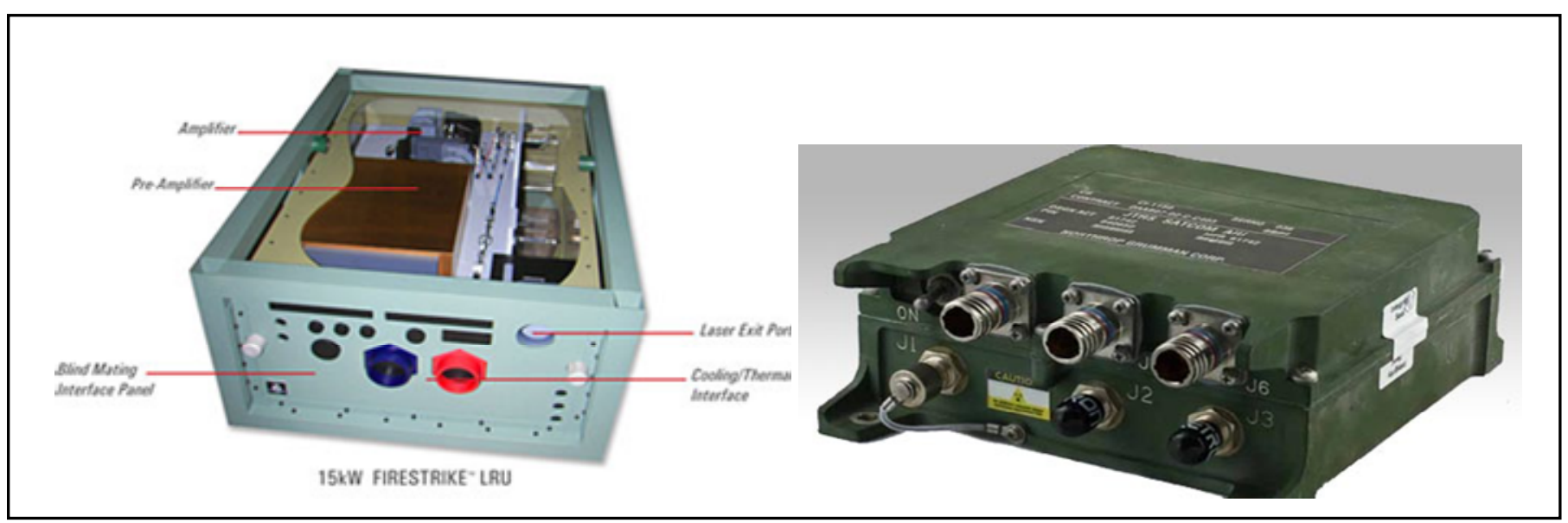

Figure 1: LRU

\subsection{Vibration Response Spectrum(VRS)}

Response Spectrum (VRS) is the Root Mean Square (RMS) absolute acceleration response of a set of Single The Vibration Degree of Freedom (SDOF) oscillators to an Acceleration Power Spectral Density (APSD) base input. The VRS is a measure of an APSD environment's severity in terms of its potential to induce a large response in a set of SDOF oscillators. By comparing the VRS of two APSD environments, the severity of the two environments can be compared.

The VRS computation technique involves computing the frequency response of each oscillator of natural frequency $f_{\mathrm{n}}$ and damping ratio $\xi$ to the base acceleration APSD by multiplying the base APSD by the SDOF Frequency Response Function (FRF). Then the RMS response is computed by numerical integration of the frequency SDOF response. The resulting equation for the acceleration vibration response is presented in equation (1) for the given natural frequency and damping.

$$
\begin{aligned}
& \ddot{\mathrm{x}}_{\mathrm{RMS}}\left(\mathrm{f}_{\mathrm{n}}, \xi\right)=\sqrt{\sum_{i=1}^{N} \frac{1+\left(2 \xi \rho_{\mathrm{i}}\right)^{2}}{\left(1-\rho_{\mathrm{i}}{ }^{2}\right)^{2}+\left(2 \xi \rho_{\mathrm{i}}\right)^{2}} \mathrm{Y}_{\mathrm{APSD}}\left(\mathrm{f}_{\mathrm{i}}\right) \Delta \mathrm{f}_{\mathrm{i}}} \quad \text { Equation (1) } \\
& \text { where, } \rho_{i}=f_{\mathrm{i}} / f_{\mathrm{n}} \& f_{\mathrm{i}}-\text { Input Frequency }\left(20<f_{\mathrm{i}}<2\right.
\end{aligned}
$$

In general, the damping ratio is taken as $\xi=0.05(\mathrm{Q}=10)$ and considered same for all SDOF systems. This gives $1 \sigma$ acceleration response for that natural frequency and damping. The equation (1) is used for computing the response for the base APSD to each oscillator natural frequency from 20 to $2000 \mathrm{~Hz}$ at $1 / 24$ octave frequency interval to arrive at the vibration response. This $1 \sigma$ acceleration response is usually plotted with respect to the oscillator natural frequency from 20 to $2000 \mathrm{~Hz}$ and is called vibration response spectrum.

The graphical representation of computation of Vibration Response Spectrum is illustrated in figure 2. 


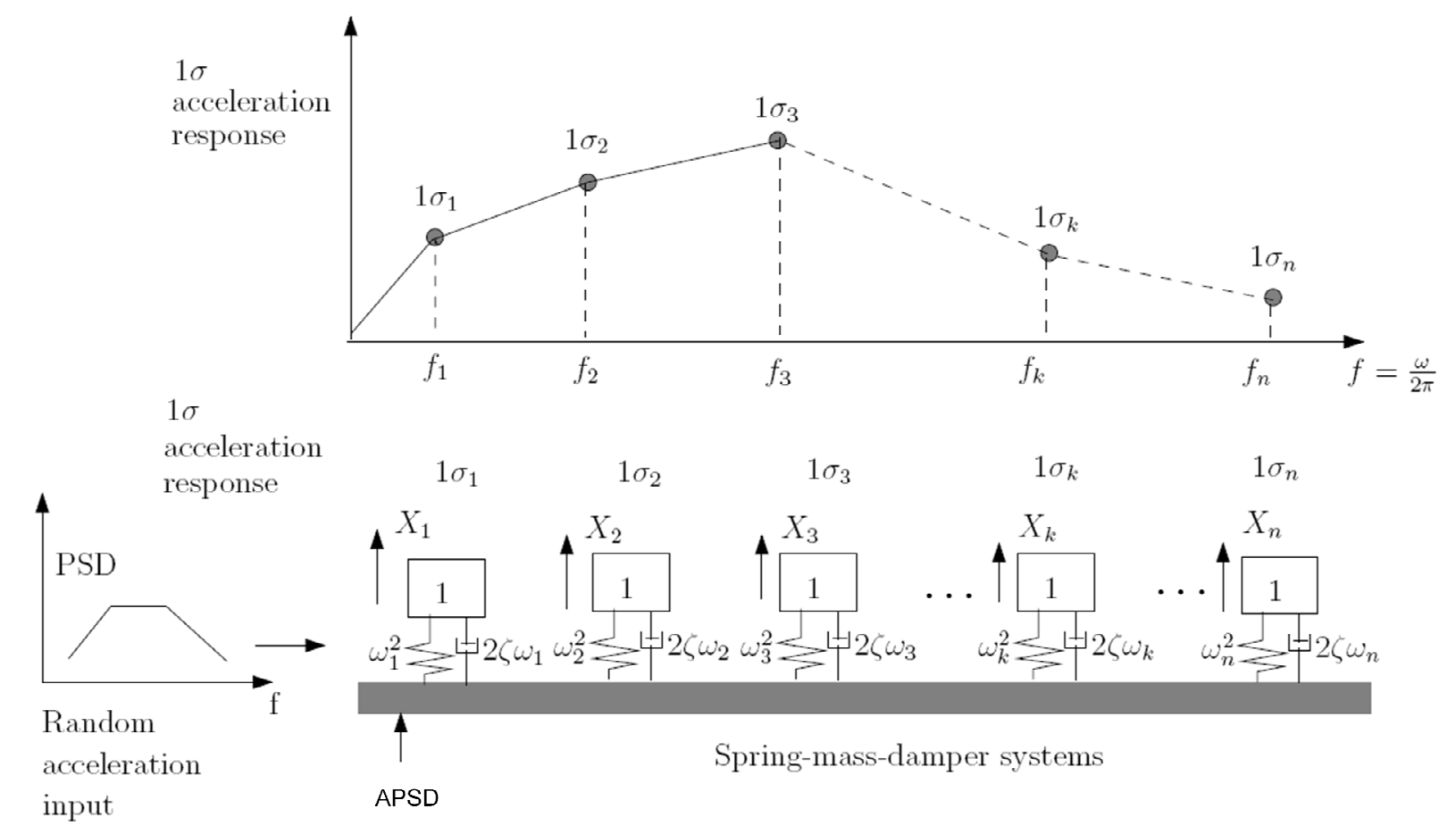

Figure 2 : Development of Vibration Response Spectrum

\section{MEASUREMENT}

\section{METHODOLOGY}

As part of the project work, the flight test instrumentation is carried out to measure the levels of vibration in terms of acceleration experienced close to the mounting location where the airborne LRU is installed. The piezoelectric accelerometers are used for measurement. The accelerometers are connected to the Data Acquisition System (DAS) and the DAS is connected to a Laptop through Ethernet LAN for recording the data through the LMS software.

The Laptop through the LMS® software records the vibration acceleration levels. The in-flight measurement is undertaken at different flight phases (taxi, takeoff, climb, cruise, descent and landing). Instead of continuous recording in each phase, the recording was done as different events at different times in each phase to increase the randomness of the vibration. The auto-power spectral densities recorded in the laptop through the LMS software are extracted from each event at the frequencies from 20 to $2000 \mathrm{~Hz}$. The maximum of all the events in each flight phase is considered for analysis. For arriving at the input vibration levels at every location of the LRUs, at every frequency from 20 to $2000 \mathrm{~Hz}$, the maximum of all the flight phases is taken as the measured acceleration PSD for further analysis.

\subsection{Qualification Level From MIL -STD}

The MIL-STD 810 random vibration qualification chosen for the development of the LRU is as shown in the figure 3. LRU have to be qualified for this level in each axis for duration of 01 hour. Further, the same levels are used for the acceptance test. However, for acceptance testing, the duration is reduced to 5 minutes in each axis.

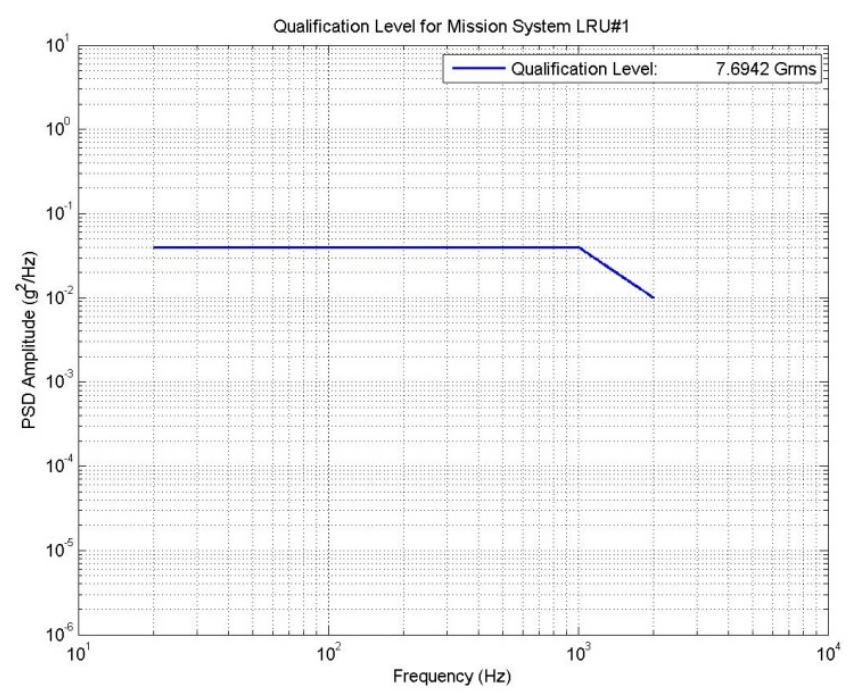

Figure 3: Qualification Level as per Mil Std. 810 considered 
This qualification level is considered as more and the same standard informs that wherever is possible it is to be tailored from the actual flight measurement. Hence, it is prudent to consider the measurement and arrive at the tailoring value.

\subsection{In-Flight Vibration Level Measurement}

The flight test instrumentation of installing the accelerometers close to the LRU mounting locations and measurement through the Data Acquisition System and recording through LMS software are carried out in ground to check the functionality of accelerometer. After the successful testing of the set-up, flight testing has been carried out. The vibration levels are recorded at every flight phase viz., i) taxi, ii) takeoff iii) climb, iv) cruise, v) descend and vi) landing. At every flight phase so many times as events, the vibration levels are recorded. This is done to increase the randomness of the vibration. The measured and recorded vibration levels in Power Spectral Density with respect to frequency for one such Mission System LRU in the $\mathrm{z}$-direction during different flight phases are as shown in the following figures namely 4 to 9 for each flight phase and the same is compared with the qualification levels.

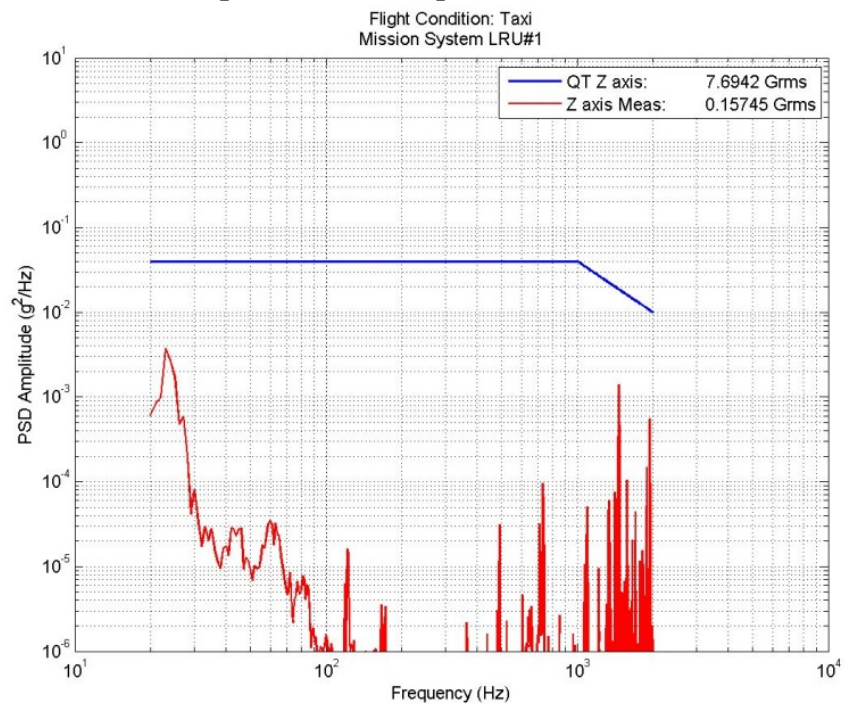

Figure 4: Measured Vibration Levels during Taxi

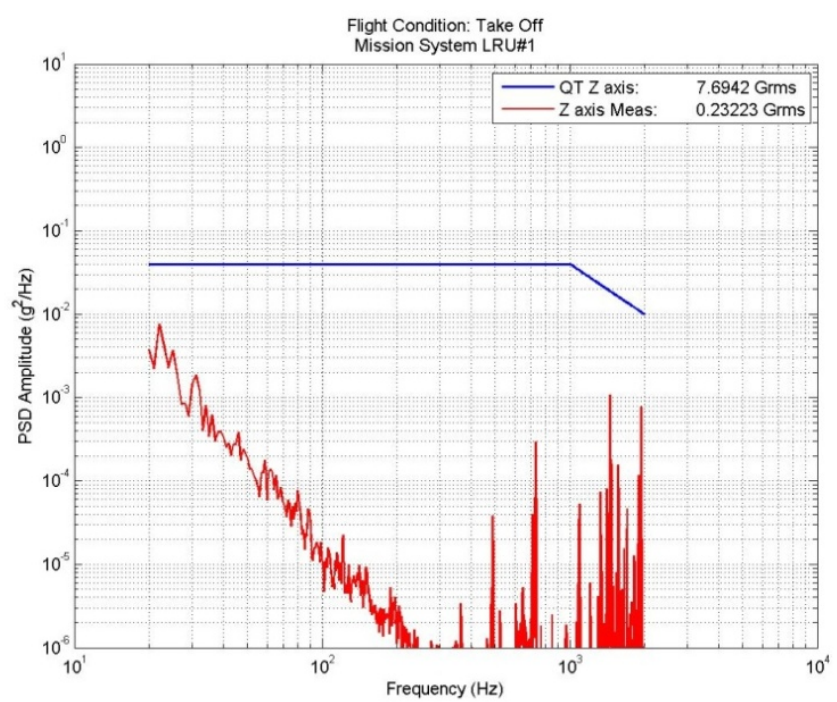

Figure 5: Measured Vibration Levels during Takeoff

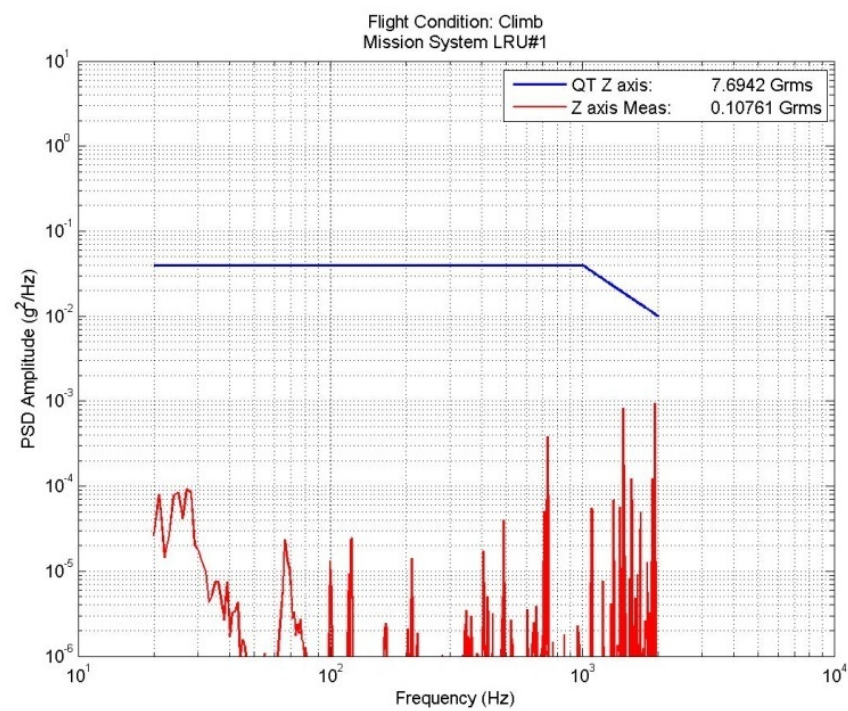

Figure 6: Measured Vibration Levels during Climb

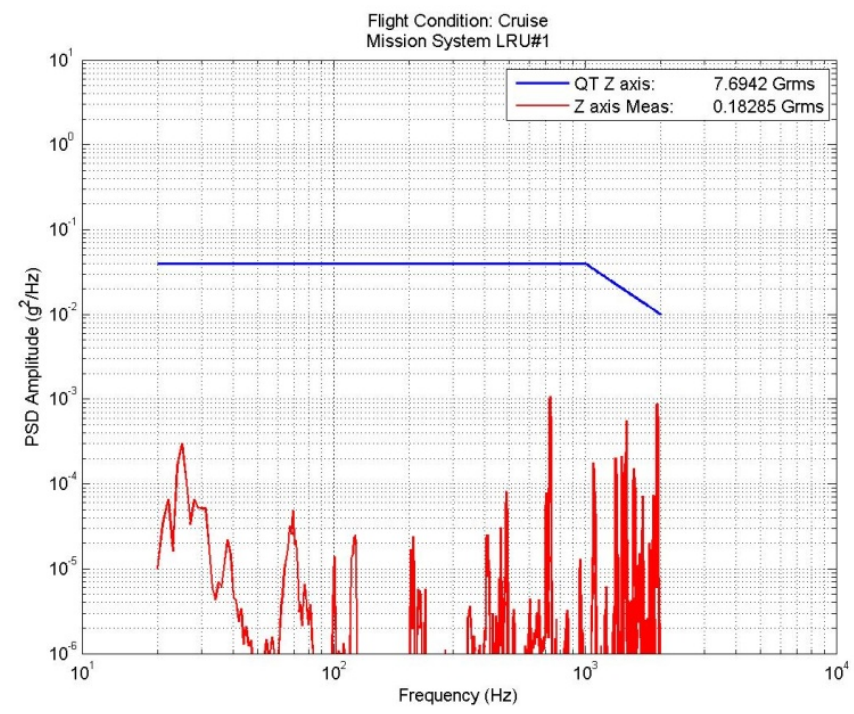

Figure 7: Measured Vibration Levels during Cruise

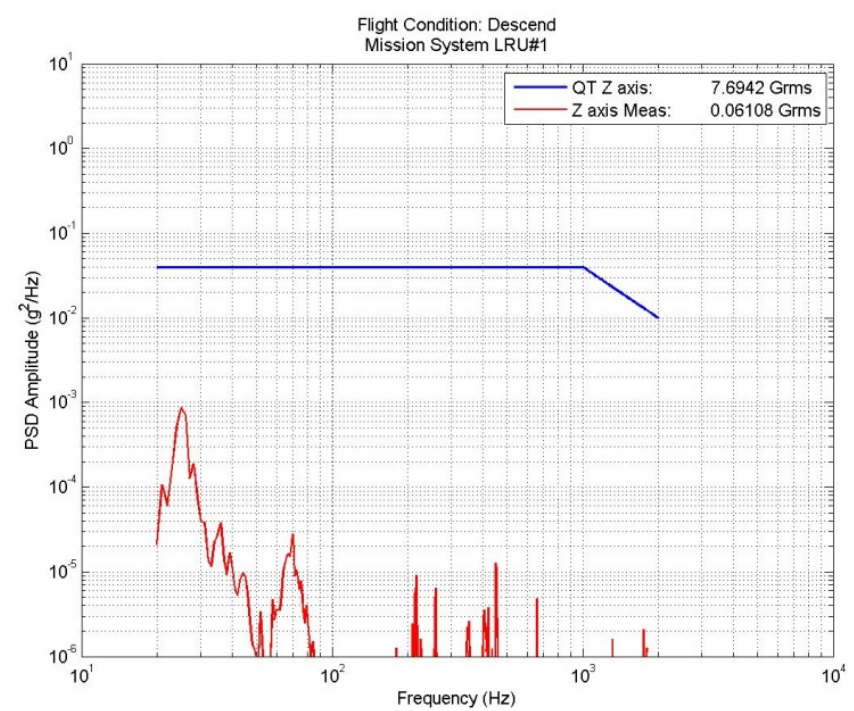

Figure 8: Measured Vibration Levels during Descend 


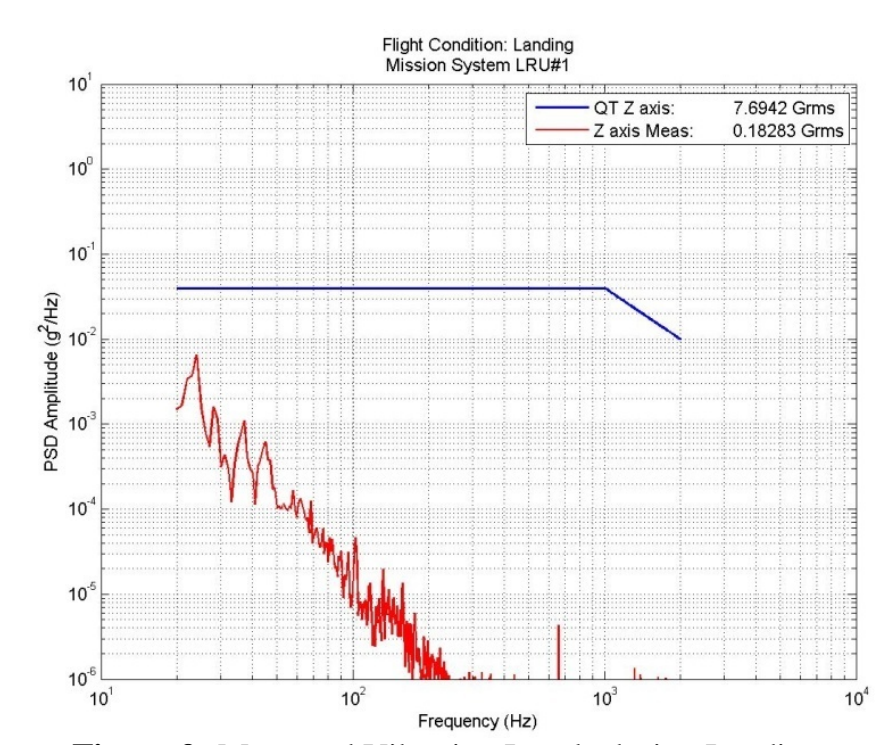

Figure 9: Measured Vibration Levels during Landing

From the figure, it is very clear that, the overall energy at each phase is much lower than the qualification level. The table 1 below mentions the overall energy level in GRMS for each phase

Table 1: Energy Levels for Different Flight Segment

\begin{tabular}{|c|c|c|}
\hline Sl. No. & Flight Segment & Overall Energy (GRMS) \\
\hline 1 & Taxi & 0.1575 \\
\hline 2 & Takeoff & 0.2322 \\
\hline 3 & Climb & 0.1076 \\
\hline 4 & Cruise & 0.1829 \\
\hline 5 & Descend & 0.0611 \\
\hline 6 & Landing & 0.1828 \\
\hline
\end{tabular}

The qualification level for this LRU is 7.6942 GRMS and also the PSD level have never exceeded (for whatever the frequency between $20 \mathrm{~Hz}$ to $2000 \mathrm{~Hz}$ ) the qualification level. Hence, as per the suggestion by Mil Std, it is prudent to consider the qualification test levels from the measured spectrum.

\subsection{Tailoring Methodology}

The Vibration Response Spectra is the Root Mean Square (RMS) absolute amplitude response of a set of Single Degree of Freedom (SDOF) oscillators to an Amplitude Power Spectral Density (APSD) base input. The vibration response spectra are similar to shock response spectra which are calculated from a component's base amplitude time history in place of APSD. The VRS is a measure of an APSD environment's severity in terms of its potential to induce a large response in a set of SDOF oscillators. By comparing the VRS of two APSD environments, the severity of the two environments can be compared. The VRS is estimated by solving the typical absolute amplitude response to a SDOF system

The VRS computation technique involves computing the frequency response of each oscillator of natural frequency $f_{\mathbf{n}}$ and damping ratio $\xi$ to the base amplitude APSD by multiplying the base APSD by the SDOF Frequency Response Function (FRF). Then the RMS response is computed by numerical integration of the frequency SDOF response. The resulting equation for the amplitude vibration response is presented for the given natural frequency and damping. The RMS absolute amplitude response is plotted with the natural frequency.

$$
\ddot{\mathrm{x}}_{\mathrm{RMS}}\left(\mathrm{f}_{\mathrm{n}}, \xi\right)=\sqrt{\sum_{i=1}^{N} \frac{1+\left(2 \xi \rho_{\mathrm{i}}\right)^{2}}{\left(1-\rho_{\mathrm{i}}^{2}\right)^{2}+\left(2 \xi \rho_{\mathrm{i}}\right)^{2}} \mathrm{Y}_{\mathrm{APSD}}\left(\mathrm{f}_{\mathrm{i}}\right) \Delta \mathrm{f}_{\mathrm{i}}}
$$

where, $\rho_{i}=f_{\mathrm{i}} / f_{\mathrm{n}} \& f_{\mathrm{i}}-$ Input Frequency $\left(20<f_{\mathrm{i}}<2000 \mathrm{~Hz}\right)$

Vibration Response Spectra is a plotted between the acceleration responses (GRMS) of single degree of freedom system with the natural frequency. GRMS response is equal to standard deviation for zero mean; hence RMS value of acceleration indicates the severity level of vibration.

The tailoring methodology involves first estimation of Maximum Expected Flight Level from the measurement which involves the following:

* At every frequency from $20 \mathrm{~Hz}$ to $2000 \mathrm{~Hz}$, the maximum of all the flight segments in terms of acceleration power spectral density is taken. This is considered as the measured acceleration power spectral density.

* Calculate the vibration response spectrum of this acceleration power spectral density.

* Divide the PSD curve of flight data into required number of break points.

* Take power spectral density value of these break points. Impose optional constraints, such as each slope must have an absolute value of $-6 \mathrm{~dB} /$ octave or less

* Again calculate the vibration response spectrum of the interpolated power spectral density.

* Compare this vibration response spectrum with the flight vibration response spectrum

* This procedure is continued iteratively through trial and error, such that at every frequency, the measured vibration response spectrum is enveloped by the vibration response spectra of the proposed PSD spectra.

The above said procedure is followed for the case of Mission System LRU \#1 as explained in the previous section. The break points chosen are at frequencies $80 \mathrm{~Hz}$ and $1000 \mathrm{~Hz}$ based on the similarity in the guidelines as put across in Mil-Std 810. 


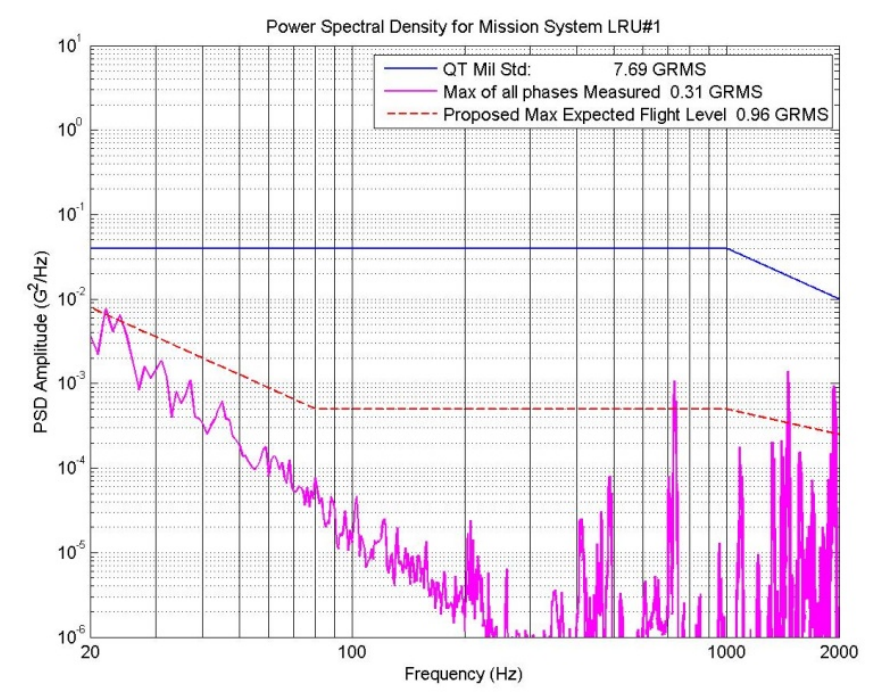

Figure 10: Power Spectral Density for Mission System LRU\#1

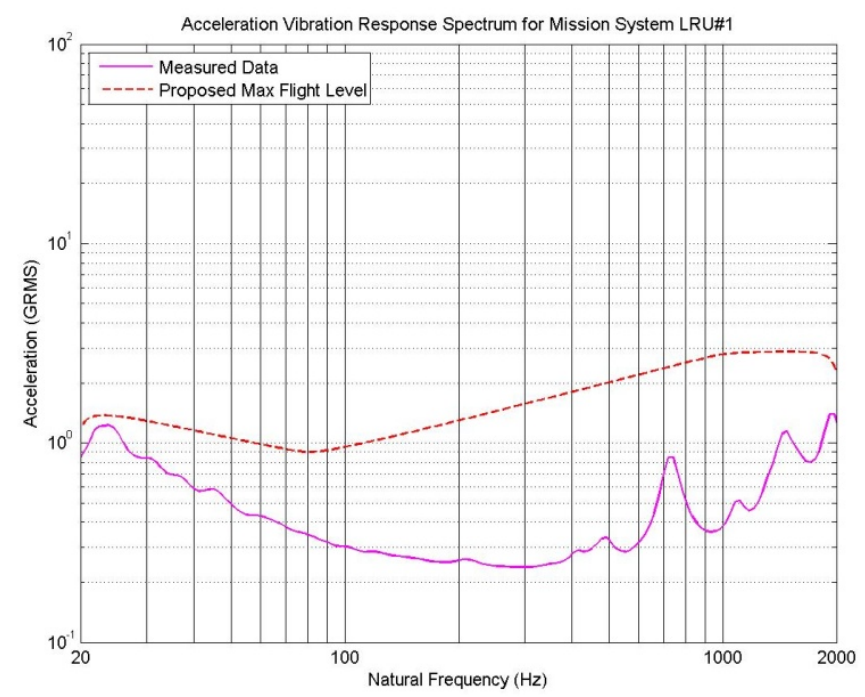

Figure 11: VRS of Measured and Proposed Excitation Power Spectral Density

From figures 10 and 11, it is clearly seen that the measured maximum of all the phases have an energy level of 0.31 GRMS compared to the qualification level of 7.69 GRMS. Considering the measured spectrum and tweaking the proposed power spectral density with linear variation with respect to frequency in log-log plot, the vibration response spectra is arrived. The proposed (Maximum Expected Flight Level) is obtained by ensuring that at no point in the acceleration vibration response spectra of the measured maximum of all flight phases is less than the vibration response spectra of the proposed spectrum with minimum break points. The proposed maximum expected flight vibration level is 0.96 GRMS.

The break points at $80 \mathrm{~Hz}$ and $1000 \mathrm{~Hz}$ are chosen based on the similariy in the guidelines as put across in Mil - Std 810 . The following table 2 gives the frequency band and the slope used in generating the maximum expected flight level.
Table 2: Frequency Band and PSD Value

\begin{tabular}{|c|c|}
\hline Frequency (Hz) & Slope \\
\hline $20-80$ & $-6 \mathrm{~dB} /$ Octave from $0.008 \mathrm{G}^{2} / \mathrm{Hz}$ \\
\hline $80-300$ & Constant at $0.0005 \mathrm{G}^{2} / \mathrm{Hz}$ \\
\hline $300-1000$ & Constant at $0.0005 \mathrm{G}^{2} / \mathrm{Hz}$ \\
\hline $1000-2000$ & $-3 \mathrm{~dB} /$ Octave from $0.0005 \mathrm{G}^{2} / \mathrm{Hz}$ \\
\hline
\end{tabular}

Table 3: Maximum Expected Flight Level PSD for Mission System LRU\#1

\begin{tabular}{|c|c|}
\hline \multicolumn{2}{|c|}{$\begin{array}{c}\text { Power Spectral Density for Mission System LRU\#1 } \\
\text { Maximum Expected Flight Level } \\
0.96 \text { GRMS Overall }\end{array}$} \\
\hline $\begin{array}{c}\text { Frequency } \\
(\mathrm{Hz})\end{array}$ & $\begin{array}{c}\text { APSD } \\
\left(\mathrm{G}^{2} / \mathrm{Hz}\right)\end{array}$ \\
\hline 20 & 0.008 \\
\hline 80 & 0.0005 \\
\hline 300 & 0.0005 \\
\hline 1000 & 0.0005 \\
\hline 2000 & 0.00025 \\
\hline
\end{tabular}

\subsection{Test Levels}

From the maximum expected flight level in PSD, two more test levels are require to derived. The first level called as acceptance test level, every component / unit must pass the acceptance test level. This level should be at least so severe that it uncovers the latent defects present in parts /units.

The second level which is $+6 \mathrm{~dB}$ higher than the first level (acceptance level) called as qualification level, and this level is used to check the any problem related with design integrity. Very few units/parts are passed through the qualification test level and these units are not used for functionality.

From the above study, it is clear that the LRU which to be qualified for the Mil-std would be over tested and hence over design which would cost more time, energy and money. Hence this proposed methodology would aid to reduce over testing of the designed and developed LRU.

\section{CONCLUSION AND COMMENTS}

In this paper, the idea of Random Vibration Specification tailoring based on the concept of Vibration Response Spectra is explained. The same procedure is adapted for one of the LRUs installed in a military aircraft. It was found that test specification levels mentioned in the Mil Standards are higher than what it can be obtained from the measurement. Though the measurement process is expensive (Instrumentation, Flight Testing, etc.,), compared to the amount of time, energy and cost involved in developing an LRU and qualifying it for the standards it is relatively less. Furthermore, the Mil Standards guidelines also recommend for measurement and tailoring than directly using the levels as specified in the Mil Standard document. 
The margin of $+6 \mathrm{~dB} /+3 \mathrm{~dB}$ over and above the maximum expected flight level arrived based on the vibration response spectrum enveloping strategy is based on compression of time for testing. In a vibration shaker table, for qualifying an item, it is not possible to keep doing the test for its life with maximum expected flight level. To reduce the time, this margin is utilized as a standard practice. However, the margin may be arrived based on the fatigue damage potential based on Palmgren Miner's rule. This may be considered as the future scope of work.

The fatigue damage estimation could be carried out either in time domain or in frequency domain. In the time domain, the rain-flow counting strategy to be adapted whereas in the frequency domain, the fatigue damage spectra could be estimated directly from the acceleration power spectral densities with the help of standard equations. This may be the future extension of this paper.

\section{REFERENCE}

[1]. C. Lalanne. Mechanical Vibration \& Shock, volume 2. London : Hermes Penton Ltd., 2002.

[2]. C. Lalanne. Mechanical Vibration \& Shock, volume 5. London : Hermes Penton Ltd., 2002.

[3]. D.E.Newland "An Introduction to Random Vibrations, Spectral \& Wavelet Analysis" third Edition, Dover Publications, Inc, April 3,201

[4]. Tom Irvine "An Introduction to the Vibration Response Spectrum Revision D” June 16, 2009

[5]. William T Thomson "Theory of Vibration with Applications" Pearson Education Asia Limited \& Tsinghua University Press.

[6]. Bendat, JS. Probability functions for random responses: prediction of peaks, fatigue damage and

catastrophic failures. NASA report on contract NAS-5-4590. 1964.

\section{BIOGRAPHIES}

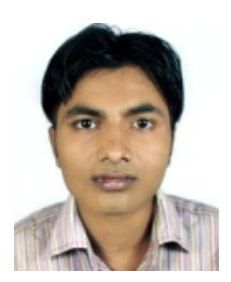

Bipin Kumar Das, M.Tech in production Technology session 2013-15,Production Engg., B.I.T Sindri, Dhanbad, Jharkhand and completed his M.Tech Project From Centre For Airborne Systems, DRDO, Bangalore.

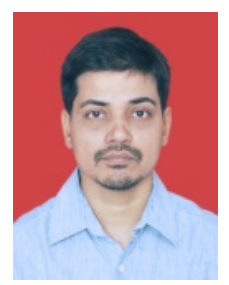

Prakash Kumar, Assistant Professor, Deptt. of Production Engg.,B.I.T.Sindri, Dhanbad, Jharkhand, serving the Institution since 2000. 